\title{
Cigarette smoking among in-school adolescents in Yilo Krobo municipality in the Eastern Region of Ghana
}

\author{
Akosua A. Owusu-Sarpong ${ }^{1}$ and Kwame Agbeshie ${ }^{2}$
}

Ghana Med J 2019; 53(4): 273-278 doi: http://dx.doi.org/10.4314/gmj.v53i4.4

\author{
${ }^{1}$ Lower Manya Krobo Health Directorate, P. O. Box 64, Odumase, Ghana \\ ${ }^{2}$ Yilo Krobo Health Directorate, P.O. Box 39, Somanya, Ghana
}

Corresponding author: Akosua Agyeiwaa Owusu-Sarpong

Conflict of interest: None declared

E-mail: akos_owususarpong@yahoo.com

\section{SUMMARY}

Background: Adolescent cigarette smoking is of public health importance since many adult smokers had initiated the habit as adolescents. This study aims to determine the prevalence of cigarette smoking among in-school adolescents in Yilo Krobo Municipality, Ghana and factors associated with cigarette smoking.

Methods: A school-based cross-sectional analytic study was conducted in February 2017 in Yilo Krobo Municipality in the Eastern Region of Ghana. A stratified random sampling method was applied to select 700 students. After obtaining informed consent, structured questionnaires were administered to collect information on demographic characteristics, behaviours, family, peer and school factors. Data was entered into SPSS and analysed with level of significant as p-value of less than 0.05 . Univariate, bivariate and multivariate analysis were applied to determine prevalence and risk factors of cigarette smoking.

Results: A total of 700 students participated in the study and the prevalence of cigarette smoking was $14.3 \%$ (100) and $77.5 \%$ (76) were introduced to smoking by their peers. Those who started smoking cigarette at the age of 10 years and below were $32 \%$ (32). Factors associated with cigarette smoking were being in JHS 1 (AOR:2.23, p=0.006), close friends smoking cigarette (AOR: 2.26, $\mathrm{p}=0.001$ ), having drank alcohol before (AOR: 6.0, $\mathrm{p}<0.001$ ) and having ever used marijuana (AOR: 6.48, $\mathrm{p}<0.001$ ). However, recognizing marijuana usage to be wrong was protective against cigarette smoking (AOR: $0.58, \mathrm{p}=0.006$ ).

Conclusion: Cigarette smoking among in-school adolescents exists in Yilo Krobo Municipality and school-based interventions such as counselling services on substance use should be implemented to address these behaviours.

Funding: No external funding was received to conduct the study

Keyword: Cigarette-smoking, Adolescents, Prevalence, Factors, Ghana

\section{INTRODUCTION}

Adolescent cigarette smoking is of public health importance since many adult smokers had initiated the habit as adolescents. Adolescents are people within the age group of 10 to 19 years and this marks the adolescence which is a developmental stage. A study conducted in USA showed a prevalence of $15.9 \%$ of cigarette smoking among $12^{\text {th }}$ graders. ${ }^{1}$ Also smoking among adolescents has short to medium term health effects in the smokers as well as peers who may be exposed to environmental smoke. Smoking in adolescents may be a marker of other harmful lifestyles such as engagement in illicit drug use, alcohol use, psychiatric illnesses and sexual intercourse. ${ }^{2} \mathrm{~A}$ study conducted by the Centres for Disease Control and Prevention (CDC) in Kurdistan-Iraq reported the prevalence of tobacco use including cigarette smoking among in-school adolescents as $11.9 \%$.
The study further found that among current smokers boys were significantly more likely than girls $(21.0 \%$ versus $2.1 \%$ ) to smoke cigarette. ${ }^{3}$ Another study conducted among in-school adolescents in Lithuania found the prevalence of cigarette smoking to be $35.8 \%$ and $27.1 \%$ among males and females respectively. ${ }^{4} \mathrm{~A}$ study conducted in Khartoum state in Nigeria showed smoking prevalence among adolescents to be $13.6 \%$ and students in public school were more likely to be smokers $(10.7 \%)$ compared with those in private school $(2.9 \%)$ with age of initiation being as early as 11 years old. 5,6

A comprehensive report of global adolescent smoking patterns $^{3}$ has shown in general male predominance is high in Africa and Asia, while in the United States and parts of Europe, the gap between the sexes is limited. 


\section{Original Article}

The differences may have to do with cultural acceptability of female smoking.

A school-based study among selected Junior secondary schools in Ghana by Wellington et al, reported that of 1,917 respondents, $14 \%$ had ever smoked cigarette, $19 \%$ currently use a form of tobacco. ${ }^{4}$ Factors found to be positively associated with cigarette smoking among adolescents were exposure to tobacco advertisement, smoking in a parent, smoking in a best friend, emotional problems including depression and recent negative life events. ${ }^{7}$

Studies have shown that those who use alcohol, cigarette or marijuana were found to be 2-6 times as likely to have had more than one sexual partner in the last year indicating a clear association. ${ }^{8}$ Tobacco use among adolescents is therefore of a public health concern since it has other health related problems. Initiation of tobacco use among adolescents can result in tobacco use disorder since the adolescents' brains are still developing, nicotine has effects on the brain's reward system and brain regions involved in emotional and cognitive functions. ${ }^{9}$

However Tobacco control regulations 2016 (L.I 2247) and Part six of Ghana Public Health Act, 2012 (Act 851) among other provisions prohibit sale of cigarette to minors, that is people aged less than 18 years. ${ }^{10}$ Studies suggest that the nicotine-related changes to these areas of the brain during adolescence may perpetuate continued tobacco use into adulthood.

These changes also contribute to a higher rate of other substance use disorders among people who use tobacco during adolescence, sometimes referred to as a "gateway" effect. ${ }^{11}$ This study aims to determine the prevalence of cigarette smoking among in-school adolescents in Yilo Krobo Municipality and factors associated with cigarette smoking. This will provide database to design interventions to address in-school adolescents cigarette smoking.

\section{METHODS}

The study was a school based cross-sectional analytic study carried out in Yilo Krobo Municipality in the Eastern Region of Ghana from $16^{\text {th }}$ February to $20^{\text {th }}$ March 2017. The municipality has a population of 97,466 with adolescent population of $18,519 .{ }^{12}$

The study adhered to the tenets of Helsinki declaration and ethical approval was granted by Ghana Health Service Ethics Review Board (GHS-ERC: 2/11/16). Adolescents aged 10 to 19 years from high schools in the Municipality took part in the study and a total sample size of 700 was used for the study. In order to ensure validity, a stratified random sampling method was employed to select the students from the schools.

A list of all Junior high schools and senior high schools in the Municipality was obtained from Ghana Education Service. The junior high schools were separated from the senior high schools to form different strata. The junior high schools which were 54 in number were further grouped into urban schools and rural schools to form two strata and sampling frame with the listing of the schools was formed for each stratum.

Four junior high schools were randomly selected from rural stratum and three junior high schools from the urban stratum by use of balloting to obtain seven JHS. In the schools, registers containing all the names of JHS students were obtained and Stata was used to generate and randomly select 50 students from each school to make a total of 350 students.

The two Senior high schools in the municipal formed another stratum and 175 students were randomly selected from each SHS school through balloting to get a total of 350 students from the SHS. A total of 700 students were then enrolled into the study. Inclusion criteria were adolescents aged between 10-19 years schooling in Yilo Krobo Municipality, who were in JHS or SHS and in the selected study schools.

Newly designed structured questionnaire was used to collect quantitative data. Twenty paramedical staff with three supervisors were intensively trained for two days on the questionnaire administration and data entry to ensure quality in data collection process. They were then divided into teams comprising of two members to form ten teams.

To ensure validity and reliability, the questionnaire was pre-tested in selected schools in a neighbouring district with similar characteristics to the study site by the teams after which a final one-day training was conducted to correct any problems detected in its administration. Written informed consent was obtained from all participating students above 18 years.

For participants below 18 years, consent was obtained from parents/guardians through writing to explain the study and requested for their endorsement of the consent forms. This was followed by endorsement of an assent form by these under-aged participants. An informed consent or assent form was read out in the appropriate language (English) to them outlining the risks and benefits of being interviewed and giving them the opportunity to decline to be interviewed or to discontinue the interview at any time. 
Thereafter, the questionnaires were administered to the students in the classroom under the supervision of their teachers and the data collectors. To ensure data quality, the data was edited and mistakes rectified on the field by trained supervisors.

\section{Data Analysis}

The data was entered using SPSS version 21 and analysed in SPSS and Stata 13MP. Each question was assigned a code for the purpose of data cleaning, entry and analysis. Completed questions were verified before entry and cleaning in the Statistical Package for Social Services (SPSS) version 24 and then exported and analysed using Stata $13 \mathrm{MP}$.

The variable assessed were categorized and presented using their frequencies and percentages and then shown in tables in the results section. Concerning the analytic aspect, outcome variable was cigarette smoking and exposure variables included socio demographic characteristics, parental factors, peer factors and behavioural factors. In determining the factors associated with cigarette smoking among in-school adolescents, first the Chisquare test of independence was used.

This was used to test the associations between the independent variables such as socio- demographic, personal, peer factors, parental and adolescent risky behaviours factors and the outcome variable, that is cigarette smoking. The Chi square figures are reported with its corresponding $\mathrm{p}$-value (significant at $\mathrm{p}<0.05$ ).

The logistic regression analysis was used to identify the significant factors associated with cigarette smoking controlling for other variables. The associated adjusted Odds Ratios (AOR) were reported with their $95 \%$ Confidence intervals $(\mathrm{CI})$ and $\mathrm{p}$-values (significant at $\mathrm{p}<0.05$ ).

\section{RESULTS}

A total of 700 students participated in the study and the age range of participants were 12 to 19 years. Participants who were 14 years and below formed $32.7 \%$ (229), those between 15 years to 17 years were $53 \%$ (371) and those who were 18 years and above were $14.3 \%$ (100).

Participants from senior high school (SHS) were 50\% (350) and those from junior high school (JHS) were also $50 \%$ (350). Male respondents were $48 \%$ (336) and females were $52 \%$ (364). Majority of respondents $(71.6 \%)$ have their parents married or cohabiting, $11.6 \%$ (81) were living with single parents and $12.6 \%$ (88) living with divorced parents.
Educational level of fathers were primary to JHS level $51.7 \%$ (362), SHS level 27.3\% (91) and tertiary level being $7.7 \%(54)$. Those without any formal education were $5.9 \%(41)$.

Table 1 Responses on cigarette smoking

\begin{tabular}{|c|c|}
\hline Variables & $\mathrm{n}(\%)$ \\
\hline $\begin{array}{l}\text { Have you ever smoked cigarette before? }(n=700) \\
\text { Yes }\end{array}$ & $100(14.3)$ \\
\hline No & $600(85.5)$ \\
\hline \multicolumn{2}{|c|}{$\begin{array}{l}\text { How old were you when you smoked a whole cigarette } \\
\text { for the first time }(n=100)\end{array}$} \\
\hline I have never smoked a whole cigarette & $22(22.0)$ \\
\hline 10 years and below & $32(32.0)$ \\
\hline 11-14 years & $2323.0)$ \\
\hline 15 years and above & $23(23.0)$ \\
\hline \multicolumn{2}{|l|}{ Who introduced you to cigarette smoking $(n=100)$} \\
\hline No response & $2(0.0)$ \\
\hline A friend & $76(77.5)$ \\
\hline A relative & $5(5.1)$ \\
\hline Self & $17(17.4)$ \\
\hline \multicolumn{2}{|c|}{$\begin{array}{l}\text { During the past } 90 \text { days, on how many days did you } \\
\text { smoke cigarette }(n=100)\end{array}$} \\
\hline$\leq 9$ days & $90(90.0)$ \\
\hline 10 - 29 days & $6(6.0)$ \\
\hline All 90 days & $4(4.0)$ \\
\hline \multicolumn{2}{|l|}{ Do any of your close friends' smoke $(n=700)$} \\
\hline No response & $1(0.0)$ \\
\hline Yes & $132(18.9)$ \\
\hline No & $463(66.2)$ \\
\hline Don't know & $104(14.9)$ \\
\hline \multicolumn{2}{|l|}{ Do any of your parents or relatives smoke $(n=700)$} \\
\hline No response & $5(0.0)$ \\
\hline Yes & $113(16.3)$ \\
\hline No & $525(75.5)$ \\
\hline Don't know & $57(8.2)$ \\
\hline
\end{tabular}

The study showed prevalence of smoking to be $14.3 \%$ (100) among study population and 32\% (32) of those who smoked initiated smoking when they were less than 10 years. More than seventy-seven percent (76) of those who smoked were introduced to smoking by their friends and $4 \%$ (4) smoked in all 90 days indicating addiction. Interestingly all the 4\% (4) were in JHS.

The factors identified to be associated with cigarette smoking from the bivariate analysis of socio-demographic factors were being a male $\left(\mathrm{x}^{2}: 1.69, \mathrm{p}=0.015\right)$, being in the JHS $\left(\mathrm{x}^{2}: 1.72, \mathrm{p}=0.013\right)$ and having divorced parents $\left(\mathrm{x}^{2}: 1.81, \mathrm{p}=0.036\right)$.

Smoking cigarette was independently associated with having friends who smoke $\left(\mathrm{x}^{2}: 5.62, \mathrm{p}<0.001\right)$, drinking alcohol $\left(\mathrm{x}^{2}: 11.21, \mathrm{p}<0.001\right)$, marijuana use $\left(\mathrm{x}^{2}: 15.9\right.$, $\mathrm{p}<0.001)$, friend drinking alcohol $\left(\mathrm{x}^{2}: 3.89, \mathrm{p}<0.001\right)$, parents smoking cigarette $\left(\mathrm{x}^{2}: 2.15, \mathrm{p}=0.002\right)$, relative use of alcohol $\left(\mathrm{x}^{2}: 1.68, \mathrm{p}=0.018\right)$, involvement in trading activities $\left(\mathrm{x}^{2}: 1.7, \mathrm{p}=0.015\right)$ and school absenteeism $\left(\mathrm{x}^{2}\right.$ : $2.24, \mathrm{p}<0.001)$. 


\section{Original Article}

Table 2 Sociodemographic factors and cigarette smoking Cigarette smoking was independently associated with

\begin{tabular}{|c|c|c|c|c|}
\hline \multirow{3}{*}{ Variable } & \multicolumn{2}{|c|}{ Cigarette use } & \multirow{3}{*}{$\mathbf{X}^{2}$} & \multirow{3}{*}{$\begin{array}{l}\text { students who were } 14 \text { years and below }\left(\mathrm{x}^{2}: 1.9, \mathrm{p}=0.032\right) \\
\mathrm{P}_{\text {ever had sex }}\left(\mathrm{x}^{2}: 3.52, \mathrm{p}<0.001\right) \text {, multiple sexual partners } \\
\text { value } 2: 2.02, \mathrm{p}=0.019) \text {, having been forced to have sex }\left(\mathrm{x}^{2}:\right.\end{array}$} \\
\hline & Yes & No & & \\
\hline & N (\%) & N (\%) & & \\
\hline 14 & ) (17.5) & & 1.45 & $\mathrm{p}=0.005)$ and bisexual orientation $\left(\mathrm{x}^{2}: 2.55\right.$, \\
\hline Above & $60(12.8)$ & $410(87.2)$ & & \\
\hline
\end{tabular}

Sex

\begin{tabular}{|l|l|l|l|l} 
Male & $59(17.7)$ & $274(82.3)$ & 1.69 & 0.01 Table 4 Sexual behaviours and cigarette smoking
\end{tabular}

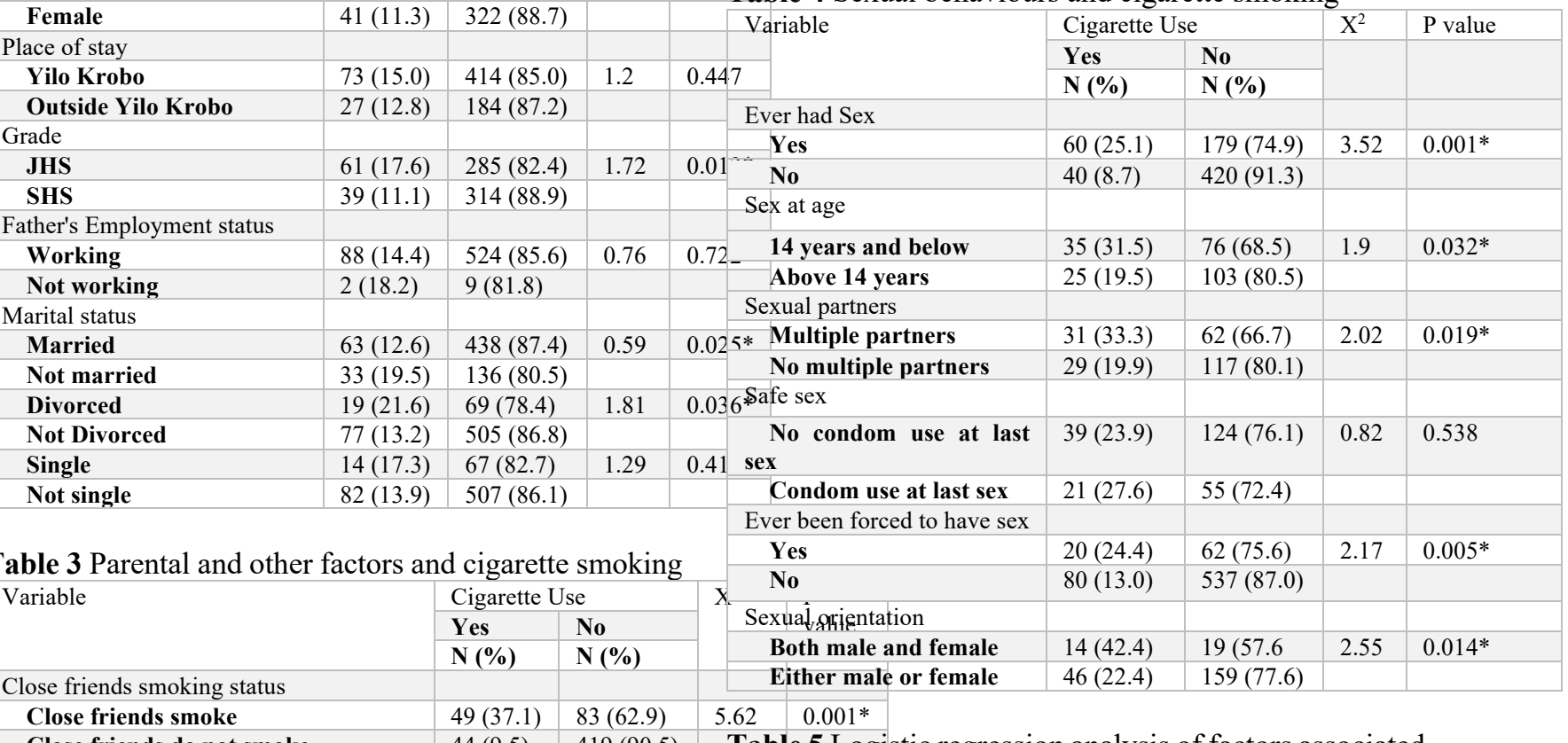

\begin{tabular}{|l|l|l|l} 
Close friends do not smoke & $44(9.5)$ & $419(90.5)$ & Table 5 Logistic regression analysis of factors associated
\end{tabular}

Parents smoking status

Parents do not smoke

Alcohol use

Ever drank alcohol

Never Use alcohol

Parents Drinking status

Parent drink

Parents don't drink

Friends drinking status

Friends drink

Friends do not drink

Relative drinking status

Relatives drink

Relatives do not drink

Neighbors drinking status

Neighbours drink

\begin{tabular}{|l|l|l}
\hline $44(9.5)$ & $419(90.5)$ & Table 5 Logistic regre \\
& & with cigarette smoking
\end{tabular}

Neighbours do not drink

Marijuana use

Ever used marijuana

\begin{tabular}{|l|l}
\hline $64(12.2)$ & $461(87.8)$
\end{tabular}

2.15ariableU2*

Never used marijuana

\begin{tabular}{l|l|l}
\hline $84(30.5)$ & $191(69.5)$ & Sex \\
\hline 1. Zurade $0.001 *$
\end{tabular}

$16(3.8) \quad 408(96.2)$

Find using mari

Ever had sex

\begin{tabular}{|l|l|l|l|}
$33(18.3)$ & $147(81.7)$ & 1 & Age at having sex \\
\hline
\end{tabular}

$67(12.9) \quad 451(87.1) \quad$ Sexual partners

\begin{tabular}{l|l|l}
49 (29.3) & $118(70.7)$ & 3. Ever been force to have sex
\end{tabular}

Sexual orientation

$51(9.6) \quad 478(90.4)$

Close friends smoke

40 (17.6) $187(82.4) \quad 16$ Garents 19 smoke

\begin{tabular}{l|l|l}
$60(11.3)$ & $472(88.7)$ & Ever drank alcohol
\end{tabular}

Relative drink

$48(16.9) \quad 236(83.1) \quad 1$ Ever used marijuana

Involved in trading or commer-

cial activities

$52(12.5) \quad 363(87.5)$

Absenteeism

$29(65.9) \quad 15(34.1)$

Involvement in trading or commercial activities

Involved in activities

$71(10.8) \quad 584(89.2)$

Not involved in activities

$60(17.6) \quad 281(82.4)$

After adjusting for other variables, significant factors as-

Absenteeism

Ever absented

Never absented

$40(11.2) \quad 318(88.8)$

150ciated 1with cigarette smoking were being in JHS 1

(AOR:2.23, $p=0.006$ ), close friends smoking cigarette

(AOR: 2.26, $\mathrm{p}=0.001$ ), having drank alcohol before $\left.65(18.9) 279(81.1) \quad 2.24 \mathrm{OR}:^{0.000^{*}}, \mathrm{p}<0.001\right)$ and having ever used marijuana $33(9.4) \quad 317(90.6)$

(AOR: 6.48, $\mathrm{p}<0.001$ ). However, recognizing marijuana usage to be wrong was protective against cigarette smoking (AOR: 0.58, $\mathrm{p}=0.006$ ). 


\section{DISCUSSION}

The prevalence of cigarette smoking was $14.3 \%$ out of which $32 \%$ of respondents started smoking cigarette when they were 10 years old and below. A similar study in USA and Nigeria shows prevalence of smoking cigarette to be $15.9 \%$ and $13.6 \%$ among adolescents. ${ }^{1,6}$ Though the USA shows a higher prevalence and a lower prevalence in Nigeria, the situation in Ghana is of great concern and needs immediate intervention. The early initiation of smoking as young as 10 years and below reported in this study is worrisome and a study conducted in Nigeria reported similar results. ${ }^{5}$ This behaviour may be as a result of cigarette and other tobacco products being easily accessible to adolescents through many commercial outlets.

The Tobacco Regulation in the country prohibits sale of tobacco products to adolescents, however poor monitoring by relevant agencies normally results in challenges with compliance making tobacco readily accessible to adolescents. Moreover, lack of adequate education of retailers, adolescents and their families on the provisions stated in the Tobacco Regulation can result in tobacco use among adolescents as some adults who smoke sometimes send adolescents to purchase cigarette for them, thereby exposing them to tobacco use.

Early initiation in cigarette smoking leads to future addiction to tobacco and other substances and may lead to health effects such as psychiatric illnesses, chronic bronchitis, lung cancers and coronary heart diseases as reported in other studies. ${ }^{2,9}$ Peers have great influence and majority (77.5\%) of adolescents who smoked mentioned that they were introduced to the habit by friends. The influence of peers on adolescent cigarette smoking has been reported in several studies. ${ }^{3,12}$

The bivariate analysis showed an independent association between cigarette smoking and school absenteeism which will affect the academic performance of the students. This has been confirmed in another study which indicates that youth who smoke cigarette have difficulties such as absenteeism and delinquent behaviours at school. ${ }^{14}$ Adolescents who smoke may get addicted to tobacco products which will end up in school absenteeism and poor academic performance. Another independent association found with cigarette smoking is parental divorce and this is explained by lack of parental supervision and support which leads to risky adolescents behaviours such as cigarette smoking and alcohol use. ${ }^{15}$ Parental divorce can also result in mental health issues such as depression among adolescents which can result in substance use such as smoking cigarette.
Another independent association to cigarette smoking found in this study is being a male and is in conformity with report of global adolescent smoking patterns ${ }^{3}$ that showed general male predominance in smoking cigarette being high in Africa and Asia. The differences in smoking between males and females may have to do with cultural acceptability of male smoking in relation to female smoking since some cultures find females smoking cigarette unacceptable.

After adjusting for other variables, being in JHS that is the younger age group is significantly associated with smoking cigarette and this may be due to early experimentation of smoking in younger years which may stop as they grow older. These findings are different from that of a school-based study conducted in Sudan which found higher incidence of smoking in the older aged adolescents compared to the younger ones. ${ }^{16}$ This presents an opportunity that early initiation of tobacco preventive programs targeted at the young adolescents will possibly prevent further abuse in older adolescents.

Close friends smoking cigarette is significantly associated with smoking among the respondents. This finding is consistent with various studies conducted elsewhere that identified significant association between smoking and close friend smoking cigarette. ${ }^{4,16}$ Peers influence is therefore great and constant exposure to friends who smoke will expedite the process of behaviour copying since adolescents have the need to be accepted by their peers. A legislative instrument aimed at regulating the activities of tobacco use in Ghana which include the ban on sale of tobacco to minors has been passed and is found in the Public Health Act. ${ }^{17}$

The use of marijuana is also significantly associated with cigarette smoking and this relationship is reported in other studies. ${ }^{18}$ Once adolescents abuse one drug, other drugs can also be abused. Furthermore, the study identified that recognizing that using marijuana is wrong, is protective against cigarette smoking which supports the identified association. Programs designed to address one type of substance use in adolescents can help in preventing the use of other substances.

\section{Limitations of the Study}

Since this study touches very sensitive and very personal issues, social desirability responding cannot be ruled out, however respondents were assured of confidentiality to assist in addressing this limitation. Also, the design of the study makes it impossible to draw inferences about the direction of relationship between the dependent and independent variables. 


\section{CONCLUSION}

The study showed a high prevalence of cigarette smoking among in-school adolescents. A majority of those who smoked were introduced to the habits by peers. Associated factors include use of other substances like marijuana and alcohol.

\section{ACKNOWLEDGEMENT}

I acknowledge the support of members of faculty of Public Health, Ghana College of Physicians and Surgeons and the staff of Yilo Krobo Health Directorate for their assistance in conducting this study.

\section{REFERENCES}

1. NIDA. Monitoring the Future Survey: High School and Youth Trends. (2017, December 14). Retrieved from https:/www.drugabuse.gov/publications/drugfacts/monitoring-future- survey-high-school-youthtrends on 21st February 2017

2. National Family Planning Board. Reproductive Health Survey 2002-2003: Jamaica Young Adults Report, Kingston, Jamaica: National Family Planning Board, 2005.

3. Centers for Disease Control and Prevention (CDC): Tobacco use among students aged 13-15 years Kurdistan Region, Iraq, 2005. MMWR Morbidity Mortality Weekly Report. 2006, 55: 556-9.

4. Wellington et al, Global Youth Tobacco Survey (GYTS), fact sheet.

http://www.cdc.gov/tobacco/global/gyts/factsheets/pdf_files/ghana.pdf (accessed 3rd April 2016)

5. Bradley Jamson, Adamson S. Muula et al. Cigarette smoking among school going adolescents in Lithuana: Results from the 2005 Global Youth tobacco survey, BMC Research Notes 2010;3:30 DOI:10.1186/1756-0500-3-130

6. Yousif M. Gadalla, Abo-mali Adil et al. Prevalence of smoking among school adolescents in Khartoum State. Sudan J Paediatr. 2012; 12(2): 44-48

7. Cheney MK, Oman RF, Vesely SK, Aspy CB, Tolma EL. Prospective associations between negative life events and youth tobacco use. Am J Health
Behav.2014;38(6):942-950.

doi:10.5993/AJHB.38.6.16.

8. Graves Karen L, Leigh Barbara C. The relationship of substance use to sexual activity among young adults in the United States. Perspectives on sexual and reproductive health. A journal of peer reviewed research, Family Planning Perspectives 1995; 27:18-22\&33,

DOI: https://doi.org/10.1363/2701895

9. Smith RF, McDonald CG, Bergstrom HC, Ehlinger DG, Brielmaier JM. Adolescent nicotine induces persisting changes in development of neural connectivity. Neurosci Biobehav Rev 2015;55:432-443.

10. Ghana Publishing. The Tobacco Control Regulations in Ghana, 2016 (LI, 2247)

11. Lydon DM, Wilson SJ, Child A, Geier CF. Adolescent brain maturation and smoking: what we know and where we're headed. Neurosci Biobehav Rev 2014;45:323-342.

12. Ghana Health Service. - Eastern Region .'District Health Information Management Systems 2 (DHIMS 2)." : Ghana Health Service, 2017

13. Myers MG. Smoking intervention with adolescent substance abusers. Initial recommendations. Journal of Substance Abuse Treatment 1999; 16:289-298, PMID: $10349601 \mathrm{M}$

14. Hoffman JH.; Welte JW, Barnes GM. Co-occurrence of alcohol and cigarette use among adolescents. Addictive Behaviors 2001; 26:63-78. PMID: 11196293

15. Conger RD et al. The family context of adolescent vulnerability and resilience to alcohol use and abuse. Sociological Studies of Children 1994;6:55-86.

16. Godeau E, Gabhainn SN. Contraceptive Use by 15Year-Old Students at their Last Sexual Intercourse. Results from 24 Countries. Arch Pediatr Adolesc Med. 2008;162(1):66-73.

17. Government Assembly Press. Part Six of Ghana's Public Health Act, 2012, Act 851. GPC/A753/350/11/2012

18. National Household Survey on Drug Abuse. Characteristics of new marijuana users. The UHSDA Report (SMA 02-3711). Rockville, MD: Substance abuse and mental health services administration 2003 